\title{
Outcomes of a Bystander Intervention Community Health Service Learning Project
}

\author{
* Kim Decker, PhD, RN, CNS \\ Clinical Assistant Professor \\ Corresponding author \\ Indiana University Bloomington School of Nursing \\ Bloomington, IN 47405 \\ kidecker@iu.edu \\ Telephone: 1(812) 855-1729 Fax: 1(812) 855-6986 \\ Desiree Hensel, Ph.D., RN, PCNS-BC, CNE \\ Associate Professor \\ Indiana University School of Nursing, SY 402 \\ Bloomington, IN, USA 47405 \\ dehensel@iu.edu \\ Leslie Fasone, Ed.S, MS \\ Assistant Dean for Women’ and Gender Affairs \\ lfasone@indiana.edu \\ Indiana University \\ Bloomington, IN 47405
}

The authors have no conflicts of interest to declare.

This is the author's manuscript of the article published in final edited form as:

Decker, K., Hensel, D., \& Fasone, L. (2016). Outcomes of a Bystander Intervention Community Health Service-Learning

Project. Nurse Educator, 41(3), 147-150. http://doi.org/10.1097/NNE.0000000000000232 


\begin{abstract}
The purpose of this article is to describe the integration and outcomes of a college bystander intervention service-learning project into a pre-licensure program’s entry-level community clinical course. Two years of data from 118 students showed that students helped improve campus safety while growing as professionals and gaining leadership and health promotion skills. Approximately one third of the students described a specific incident in which they intervened in an ambiguous situation.
\end{abstract}

Keywords: Bystander effect, Campus safety, Community health nursing, Health promotion, Nursing education

\title{
Background
}

Pre-licensure nursing students have dual roles, one as a student studying the profession and another as an active member of the college community. Preventable injuries pose a significant threat to the health of many of those college communities. Approximately 1 in 5 college females between the ages of 18 and 25 experiences an attempted or completed sexual assault and more than 599,000 college students between the ages of 18 and 24 are injured annually from an alcohol-related incident $(1,2)$. Nursing students themselves are very likely to engage in behaviors that put them at risk for alcohol-related injuries (3, 4).Therefore, it is likely that nursing students will encounter campus situations where other students need assistance. These situations provide students with everyday opportunities to engage in community health efforts very early in their nursing career. 
Bystander intervention training is one strategy being used by some colleges and universities to reduce preventable injuries (5-10). This training is based on a well-known social phenomenon, the bystander effect, where ambiguity and diffusion of responsibility result in the failure of individuals to assist others in need (11-13). The bystander intervention framework outlines five steps that bystanders, otherwise described as inactive witnesses, must go through to provide help. The steps for intervening are 1) Notice the event, 2) Interpret the event as a problem, 3) Assume personal responsibility, 4) Know the skills to help, and 5) Help (12). Bystander intervention trainings focus on increasing knowledge about the problem, teaching the skills to intervene, and increasing the bystander's confidence to perform helping actions. Oncampus trainings frequently involve teaching students to recognize the different signs leading up to a potentially problematic situation and the spectrum of ways to provide assistance and intervene (13).

To enhance injury prevention efforts, our large, public Midwestern university created a campus-wide bystander intervention initiative to promote awareness, caring, and courage among students called “Culture of Care.” This project has 4 focus areas aimed at improving sexual wellbeing, mental health, alcohol and drug awareness, and respect among students. As personal responsibility and social support for intervening increase, students are more likely to help others in need (11). Thus this student-led initiative, supported by the Dean of Students Office, asserts that student-to-student support is essential for creating a safer environment on campus. 
As generalists, professional nurses are expected to learn basic skills to improve the health and safety of communities (14). National recommendations suggest undergraduate clinical education should shift to having a greater emphasis on community settings while offering a wider variety of clinical experiences beyond the acute care setting (15). To meet these curricular needs, we created a service-learning clinical experience in a beginning-level nursing course to support the Culture of Care initiative. The research questions that guided this study were "How did the nursing students contribute to improving the campus’s well-being?” and “How did participation in the bystander intervention service-learning project help promote students’ professional development?”

\section{Method}

Over the course of 2 years, all BSN students enrolled in a required entry-level Healthy Populations clinical course $(\mathrm{N}=120)$ participated in a 4-hour bystander intervention training program. The first 2-hour session was a discussion-based presentation, led by a representative of the Culture of Care Program from the Dean of Students Office, which utilized video clips and case studies to teach students the 5 steps of the bystander intervention framework. Communication techniques were taught using "I” messages such as "I care”, “I noticed”, “I feel”, “I want”, and “I will” to help students learn how to initiate caring conversations. Students were given examples of 'stepping up’ such as calling 911 when someone has too much to drink and needs medical assistance, helping someone who has fallen off their bike or asking a friend who is upset if they are okay. University resources were also provided so students would be aware of who to contact for help with a fellow student if needed. 
A second 2-hour session was provided 1 week later where students reflected on a situation that they observed in the past week as bystanders and brainstormed ways to proactively intervene as potential bystanders in a set of case studies (Table 1). Using a service-learning framework, students then received instructions to spend a minimum of 6 hours engaging in activities of their choice that promoted at least one of the 4 Culture of Care focus areas over the course of the semester. Clinical faculty members were available by phone as students completed their Culture of Care clinical hours. Students who did not live on campus were still able to complete the assigned activity through active participation in campus activities and meeting with other members of the university community.

Students recorded their hours in their clinical logs and reflected on their experience through group discussions and in a written journal. The journal guidelines included writing a short and informal reflection on their activities and feelings surrounding their Culture of Care experience. Students were encouraged to discuss how this experience helped them develop as a nurse and if they actually intervened in a potentially bad situation.

We obtained an Institutional Review Board approval of exempt research to conduct this mixed-method study. Students were advised of their rights and given the option of not allowing their course work to be further analyzed. The researchers did not know the identity of students 
opting out of the study until after grades were posted. All student work was de-identified before undergoing further analysis.

The intended project learning outcomes were to engage in service learning and to develop professional behaviors. We used a case study design to gain a holistic understanding of how students met those project outcomes and to explore additional student and campus benefits. Quantitative data from students' time logs was mapped to qualitative data from their reflective journals using Dedoose Version 5.0.11 software (SocioCultural Research Consultants LLC, Los Angeles, California).

\section{Outcomes}

One hundred eighteen students consented to having their logs and journals analyzed. Students dedicated 960 hours to campus well-being while developing as leaders, health promotors, and professionals. Students spent their time acting as sober monitors or designated drivers (324 hours), creating alternatives to drinking activities (269 hours), joining groups or attending meetings related to the Culture of Care focus areas (177 hours), participating in community awareness events (60 hours), taking friends to Culture of Care-related seminars (75 hours), and working with small groups or individuals (78 hours).

Evidence that students improved campus safety was supported by the finding that approximately one third of the students $(\mathrm{N}=44 / 118)$ reported using their training to intervene in 
an ambiguous, potentially dangerous situation beyond acting as a pre-planned designated driver. This form of intervention was exemplified in a student's journal:

One situation that happened this night was a girl was going to leave with a guy but I knew she did not want to because we talked before we all went. I stopped her and asked if she wanted to go get food instead and although it took a lot of convincing she finally came with me and she didn’t leave with the guy. Without the skills I had learned from the Culture of Care presentations I don’t know if I would have been able to successfully help this girl. It made me feel much better about myself knowing I helped her and kept her safe.

We found that the student learning outcomes from the Culture of Care experience included many knowledge, skills and attitudes that reflected the Quality and Safety Education for Nurses (QSEN) safety and quality improvement competencies such as minimizing risk of harm and systems change (16). Moreover, student reflection journals displayed compassion, advocacy, and professional and knowledge development attributes which, along with safety and quality elements, can be linked to the American Nurses Association Code of Ethics for Nurses (17). Lastly, students grew as leaders, health promoters and professionals consistent with the American Association of Colleges of Nursing (AACN) Essentials of Baccalaureate Education for Professional Nursing Practice (14). Most student journals (111/118) reflected gaining leadership skills by coordinating events, addressing safety concerns, providing caring environments, and/or working toward system change (Table 2). Also, 61 journals included 
reflections suggesting that students grew as health promotors by learning new information about injury prevention and teaching other students. Finally, 58 journals provided evidence of professional growth including gaining activism skills and a wide range of professional values such as advocacy and self-care. One student summed up their experience by expressing:

I enjoyed spreading the message of bystander intervention, caring for those around you, and watching out for one another. I found this to be a very rewarding use of clinical hours and it opened my eyes to some of the issues on this campus and the overall culture of individual responsibility and how that needs to change and we need to work to be accountable for one another.

\section{Discussion}

Review of the data suggests that the Culture of Care service-learning project benefited the campus and fulfilled many curricular needs but also raised many important questions. Until recently, community health nursing at our institution was narrowly enacted as working one-onone with a RN preceptor in a senior-level course. This entry-level community experience was designed to expand community education, not to replace what was already in place. Still, our faculty had concerns that entry-level students may not yet have the skills needed to be successful in community settings which tend to require a high degree of autonomous practice.

To meet these concerns, faculty utilized Vygotsky’s approach to scaffolding, which is a process by which one is dynamically constructing oneself and one's environment, through the 
assistance of others who have a more developed understanding. Using scaffolding concepts, the faculty generated significant educational opportunities that reinforced the 4 different concepts from the Culture of Care initiative with which students were already familiar but in which they were not conceivably competent. These Culture of Care educational opportunities built on students' initial knowledge base and enabled them to branch out with faculty support and be competent in higher level activities (18). Consequently, our nursing students worked in a fairly independent manner with college-aged students in their natural environment to reduce preventable injuries while gaining a greater understanding of high-risk behaviors and possible intervention strategies.

During this bystander intervention service-learning project students realized that they could indeed provide needed social support and generate change in their current environment. The concept of bystander intervention is not new to healthcare. It is the foundation of public CPR efforts (19). What is unknown is if learning to be willing to intervene in ambiguous community settings will translate to acute care settings.

Our service-learning project was also consistent with QSEN, ANA, and AACN positions that professional nurses engage in systems change $(14,16,17)$. The 2011 Institute of Medicine (IOM) Recommendations for the Initiative on the Future of Nursing similarly states that nurses have great potential to lead innovative system change strategies to advance the health care system and practice environment, while functioning to the fullest degree of their education and training. This IOM report endorses that schools of nursing prepare the nursing workforce for 
leadership in all health environments by redesigning and improving practice settings to advance health (20). This Culture of Care project, analogous to the IOM report suggestions, gave novice nursing students an opportunity to exercise their nursing skills to the best of their abilities within their preliminary education and training while acquiring leadership skills and improving health environments.

Nurses, regardless of their roles in the health care system, are called upon to be leaders and advocates who have a moral responsibility to promote the health and safety of all people (17), but traditional methods in pre-licensure education have not always led to the development of strong leaders $(3,21)$. Others have used service learning as an effective strategy to cultivate leadership in pre-licensure students $(22,23)$. We also found that this service-learning project gave novice student nurses an opportunity to develop leadership skills and carried the advantage that it occurred very early in the curriculum. What is unknown is if students will scaffold on this early leadership experience to become stronger leaders by the program's end. This project was conducted in a BSN program at a single university, so the results may not be generalizable to other programs or locations.

The IOM report also encourages innovative and enriched education strategies to be developed in community settings (20). However, while educators are being called to increase community-based clinical education, only $10 \%$ of new graduates currently are employed in community settings (24). It is unknown if this early exposure to community health nursing will increase students' long-term interest in that specialty. 


\section{Summary}

The outcomes of this service-learning project were promising. We found that that this bystander intervention project was an effective and creative way to provide community health education. Understanding the exact role that this particular service-learning project and other creative yet beneficial clinical experiences could play in nursing curricula needs further research and should be part of the ongoing conversation among educators. 


\section{References}

1. Krebs CP, Lindquist CH, Warner TD, Fisher BS, Martin SL. The Campus Sexual Assault (CSA) Study. Washington, DC: US Department of Justice; 2007.

2. Hingson RW, Zha W, Weitzman ER. Magnitude of and trends in alcohol-related mortality and morbidity among US college students ages 18-24, 1998-2005. J Stud on Alcohol Drugs, Suppl. 2009;s16:12-20.

3. Hensel D, Middleton MJ, Engs RC. Drinking patterns, prelicensure nursing education, and professional identity formation. Nurs Educ Today. 2014;34(5):719-723.

4. Hensel, D, Engs, RC, Middleton, MJ. Differences in drinking patterns between female nursing and non-nursing students [published online July 9 2015]. Nurs Educ. 2015. doi: 10.1097/NNE.0000000000000200.

5. Reid CE, Irwin M, Dye H. Learning to prevent campus violence, EKU-Safe: A bystander intervention training program. KY J Excellence Coll Teach Learn. 2012;10(Article 1):918.

6. Coker AL, Cook-Craig PG, Williams CM, et al. Evaluation of Green Dot: an active bystander intervention to reduce sexual violence on college campuses. Violence Against Women. 2011;17(6):777-796.

7. Gidycz CA, Orchowski LM, Berkowitz AD. Preventing sexual aggression among college men: an evaluation of a social norms and bystander intervention program. Violence Against Women. 2011;17(6):720-742.

8. Salazar LF, Vivolo-Kantor A, Hardin J, Berkowitz A. A web-based sexual violence bystander intervention for male college students: randomized controlled trial. J Med Internet Res. 2014;16(9):e203. 
9. Moynihan, MM, Banyard VL, Arnold JS, Eckstein RP, Stapleton JG. Sisterhood may be powerful for reducing sexual and intimate partner violence: an evaluation of the Bringing in the Bystander in-person program with sorority members. Violence Against Women. 2011; 17(6): 703-719

10. Fischer P, Krueger JI, Greitemeyer T, et al. (2011). The bystander-effect: a meta-analytic review on bystander intervention in dangerous and non-dangerous emergencies. Psychol Bull. 2011;137(4):517-537.

11. Bennett S, Banyard VL, Garnhart L. To act or not to act, that is the question? Barriers and facilitators of bystander intervention. J Interpers Violence. 2014;29(3):476-496.

12. Latané B, Darley JM. The Unresponsive Bystander: Why Doesn’t He Help? New York: Appleton- Century Croft; 1970.

13. McMahon S, Banyard V L. When can I help? A conceptual framework for the prevention of sexual violence through bystander intervention. Trauma Violence Abuse. 2012;13(1): 3-14.

14. American Association of Colleges of Nursing. The Essentials of Baccalaureate Education for Professional Nursing. http://www.aacn.nche.edu/educationresources/BaccEssentials08.pdf. Published February 19 2009. Accessed July 32015.

15. Benner P, Sutphen M, Leonard V, Day L. Educating Nurses: A Call for Radical Transformation. San Francisco, CA: Jossey-Bass; 2009.

16. Cronenwett L, Sherwood G, Barnsteiner J, et al. Quality and safety education for nurses. Nurs Outlook. 2007;55(3):22-131.

17. American Nurses Association. Code of Ethics with Interpretive Statements. http://www.nursingworld.org/MainMenuCategories/EthicsStandards/CodeofEthicsforNur 
ses/Code-of-Ethics.pdf. Published 2001. Updated 2015. Accessed July 3, 2015.

18. Vygotsky L. Mind in Society: The Development of Higher Psychological Processes. Cambridge, MA: Harvard University Press; 1978.

19. Wissenberg M, et al. Association of national initiatives to improve cardiac arrest management with rates of bystander intervention and patient survival after out-of-hospital cardiac arrest. Jama. 2013;310(13):1377-1384.

20. IOM (Institute of Medicine). The Future of Nursing: Leading Change, Advancing Health. Washington, DC: The National Academies Press; 2011.

21. Hensel D, Laux M. A longitudinal study of stress, self-care, and professional identity among student nurses. Nurs Educ. 2014;39(5):227-231.

22. Foli K J, Braswell M, Kirkpatrick J, Lim E. Development of leadership behaviors in undergraduate nursing students: a service-learning approach. Nurs Educ Perspect. 2014; 35(2):76-82.

23. Groh CJ, Stallwood LG, Daniels JJ. Service-learning in nursing education: its impact on leadership and social justice. Nurs Educ Perspect. 2011;32(6):400-405.

24. National Council of State Board of Nursing. 2014 RN Practice Analysis: Linking the NCLEX-RN® Examination to Practice U.S. and Canada. https://www.ncsbn.org/15_RN_Practice_Analysis_Vol62_web.pdf. Published January 2015. Accessed July 5, 2015. 
Table 1. Bystander Intervention Case Study

\begin{tabular}{|l|}
\hline Situation 1: The Party \\
\hline $\begin{array}{l}\text { One of your friends, Sam, is hosting a party and has clearly had too much to drink. Sam's } \\
\text { speech is slurred and he/she has spilled alcohol on his/her shorts a number of times. Sam } \\
\text { continues to drink and you're concerned that the situation is getting out of hand. }\end{array}$ \\
\hline Be Prepared to Report Back to the Group: \\
\hline 1. What issues are ambiguous in this situation? \\
\hline $\begin{array}{l}\text { 2. What are some things that you can do in this situation to make sure that the situation } \\
\text { doesn't escalate? }\end{array}$ \\
\hline $\begin{array}{l}\text { 3. How might conformity or concerns about what other people think get in the way of you } \\
\text { stepping up to help? }\end{array}$ \\
\hline $\begin{array}{l}\text { 4. Name } 3 \text { direct ways to help AND } 3 \text { indirect ways to help. (Be specific and creative! This } \\
\text { could be in the moment and/or the next day) }\end{array}$ \\
\hline 5. Identify at least 2 resources you could call to help in this situation. \\
\hline 6. What are the potential costs and rewards of intervening? \\
\hline $\begin{array}{l}\text { 7. Would you want someone to do something if you were the person in this situation? If so, } \\
\text { what would you want them to do to help you? }\end{array}$ \\
\hline
\end{tabular}


Table 2. Learning Outcomes, Subcategories, Examples, and Frequencies

\begin{tabular}{|c|c|c|}
\hline \multicolumn{3}{|l|}{ Leadership } \\
\hline Subcategory & Example & Frequency \\
\hline $\begin{array}{l}\text { Addressing Safety } \\
\text { Concerns }\end{array}$ & $\begin{array}{l}\text { "I really took initiative and helping people in a way } \\
\text { that is necessary to keep people safe...I became a more } \\
\text { confident leader..." }\end{array}$ & 77 \\
\hline Coordinating Activities & $\begin{array}{l}\text { "It gave me insight on what issues may be happening } \\
\text { on our campus, how to prevent them and be a leader in } \\
\text { our community. It also felt really good to organize } \\
\text { sober activities for my friends..." }\end{array}$ & 64 \\
\hline $\begin{array}{l}\text { Providing Caring } \\
\text { Environments }\end{array}$ & $\begin{array}{l}\text { "Through these experiences, I was able to promote } \\
\text { compassion towards my peers and promote a positive } \\
\text { environment for care." }\end{array}$ & 31 \\
\hline $\begin{array}{l}\text { Working Toward } \\
\text { System Change }\end{array}$ & $\begin{array}{l}\text { "Opened my eyes to some of the issues on this campus } \\
\text { and how the overall culture of individual } \\
\text { responsibility needs to change so that we all work to } \\
\text { be accountable for one another." }\end{array}$ & 20 \\
\hline \multicolumn{3}{|l|}{ Health Promotion } \\
\hline $\begin{array}{l}\text { Teaching Other } \\
\text { Students }\end{array}$ & $\begin{array}{l}\text { "It was very rewarding to be able to educate them } \\
\text { (freshman males on sexual assault issues) and I felt I } \\
\text { truly made a difference...they greatly appreciated me } \\
\text { talking to them." }\end{array}$ & 31 \\
\hline $\begin{array}{l}\text { Gaining Injury } \\
\text { Prevention Knowledge }\end{array}$ & $\begin{array}{l}\text { "The key topic I learned was to always call if you } \\
\text { even think someone is slightly hurt from something } \\
\text { having to with alcohol.” }\end{array}$ & 61 \\
\hline \multicolumn{3}{|l|}{ Professional Growth } \\
\hline Acting as Activists & $\begin{array}{l}\text { "It was a great feeling running for violence awareness } \\
\text { and supporting the family whose daughter } \\
\text { unfortunately passed away from violence on campus." }\end{array}$ & 19 \\
\hline $\begin{array}{l}\text { Gaining Professional } \\
\text { Values }\end{array}$ & $\begin{array}{l}\text { "These Culture of Care hours have made me realize } \\
\text { why I want to be a nurse...I want to be that advocate." }\end{array}$ & 44 \\
\hline
\end{tabular}

